\title{
Failure Analysis of Fixed Frame Screw for a B-Phase Spindle of Breaker
}

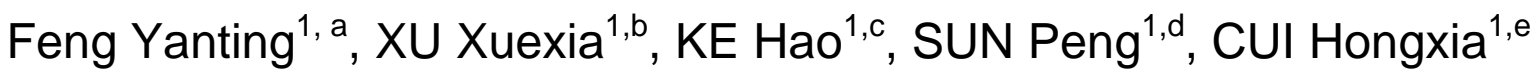 \\ ${ }^{1}$ State Grid Hebei electric power research institute, Shijiazhuang, 050021, China \\ a13503206410@139.com, ${ }^{b} x u x u e x i a 2008 @ 163 . c o m,{ }^{c h}$ epri-keh@he.sgcc.com.cn, ${ }^{d}$ hepri-sunp@h \\ e.sgcc.com.cn, ${ }^{e}$ hepri-chx@he.sgcc.com.cn
}

Keywords: Screw, fracture, stress concentration.

\begin{abstract}
The fracture causes of fixed frame bole for a B-phase spindle of breakers were discussed based on results of macroscopic inspection, chemical composition analysis, metallurgical microstructure examination, SEM fracture analysis. It was concluded that the screw deformed and cracked under shock load. Suggestions were provided in order to prevent similar accident.
\end{abstract}

\section{Introduction}

Proper and safe screw connection can ensure the demands for strength and stiffness of station structure [1]. As one of connecting components, screw plays an important role in guaranteeing safe and stable operation of transmission lines[2-3]. Therefore screw fracture analysis is necessary and instructive to avoid similar events[4-5].

During acceptance monitoring of a transmission and distribution project, two fixed frame screws for B-phase spindle of breaker of a $220 \mathrm{kV}$ composite apparatus were found to fracture. The failure causes were discussed in this paper and suggestions were provided.

\section{Experimental results and analysis}

Macro inspection of the fractured screw. The macro morphology of the fractured screw was shown in Fig.1. It could be seen that the thread tips at the root were damaged severely with about $15 \mathrm{~mm}$ in length, not surrounded the entire circle, and somewhere remained well.

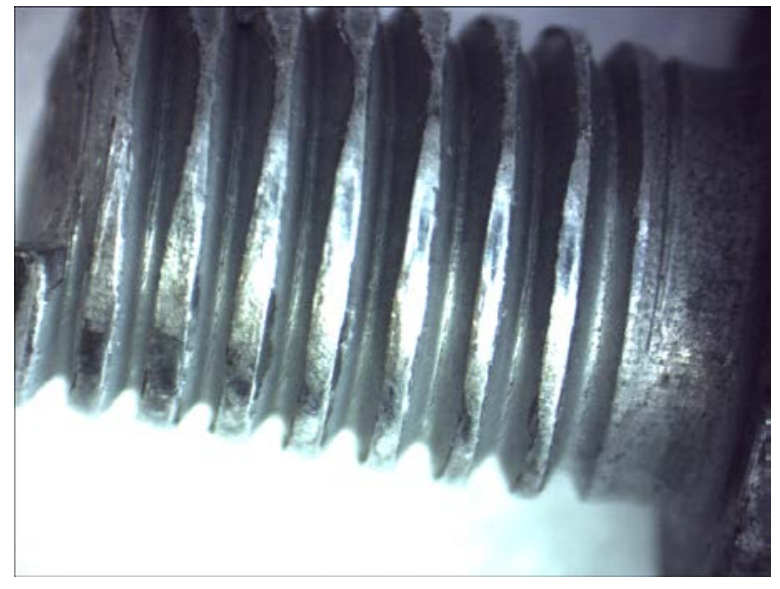

Fig.1 Damaged thread tips at the screw root Fig.2 Damage morphology on the thread surface

The damaged position was magnified for further observation indicated in Fig.2. From Fig.2 it could be found that the surface abrasion were not caused by rotating operation but by blunt beating.

Combining the results of Fig.1 and Fig.2, the scratches on the screw were not induced during the installation process. They were presumed to form afterwards.

Fig. 3 showed the condition of matching surface between screw and header. It illustrated serious squeezing traces. Whereas, of the hexagonal matching surfaces, only two surfaces in bilateral symmetry inhibited squeezing marks as indicated in Fig.4. 


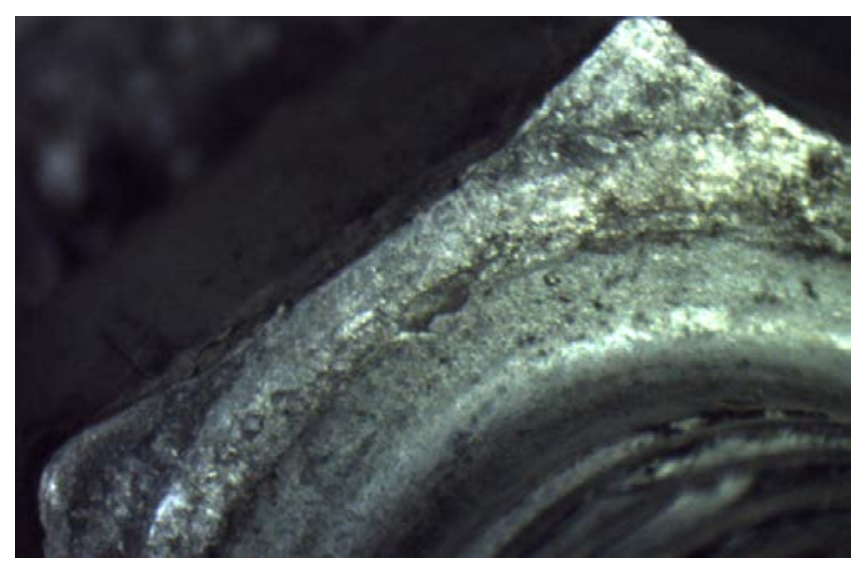

Fig.3 Damaged matching surface between screw and header

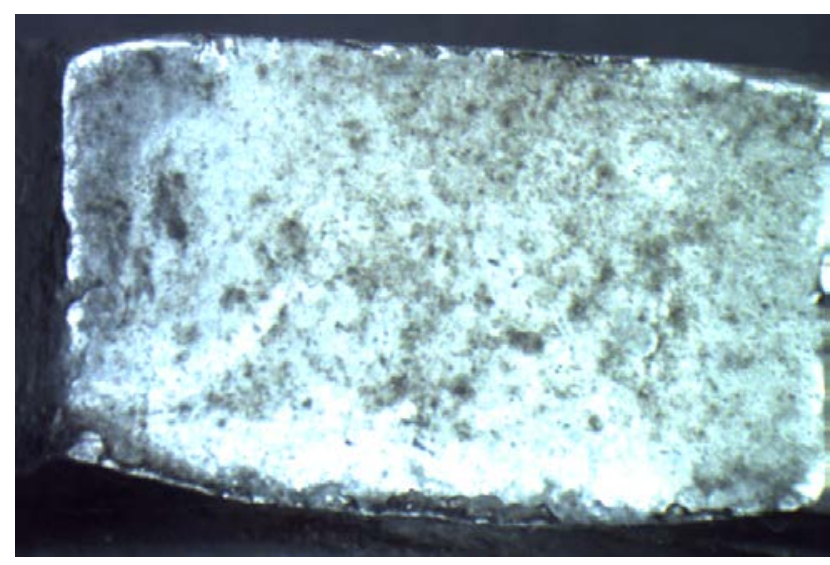

Fig.4 Squeezing traces in hexagonal matching surface matched to wrench

Further examination on screw root found that the zinc coating had cracked as shown in Fig.5, meaning that the screw happened plastic deformation. Magnification inspection found the crack did not propagate to base metal, therefore the zinc coating cracking was not the main cause of the screw failure.
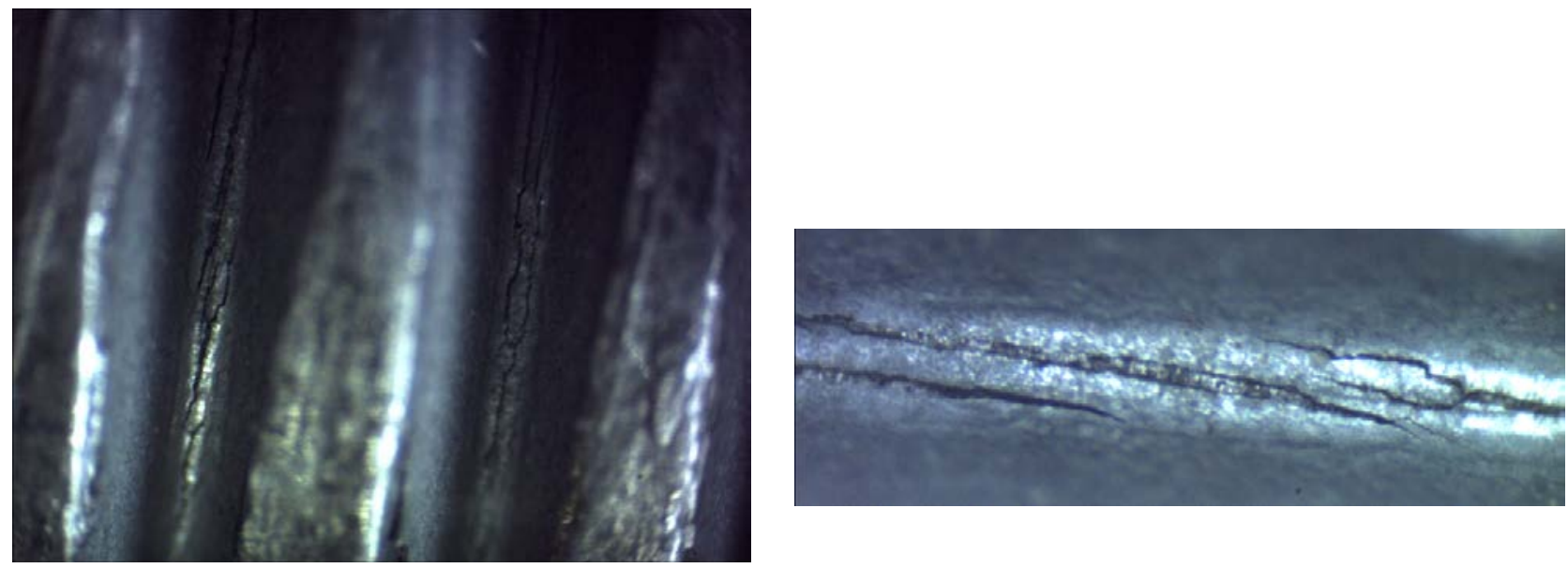

Fig.5 Zinc coating crack at the screw root

Fig.6 Zinc coating crack not propagating to base metal

Finally, the screw fracture was observed and shown in Fig.7. It was found form Fig.7 that it contained two areas with different morphologies, flat area and waffle area. Both of them appeared gray color. In addition, the morphology of fracture surface denied the possibility of twist off.

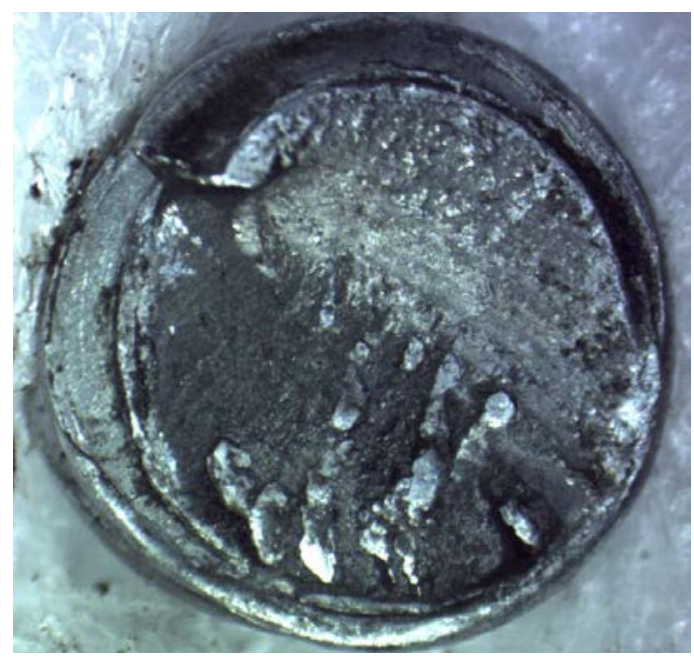

Fig.7 Fracture morphology of the screw 
Chemical composition analysis of the failure screw. The chemical composition of the screw was analyzed by ARL 3460 direct-reading spectrometer in order to examine the material. The result was given in table.1, showing that the material met with the requirements of GB/T 3098.1-2000 standard for 6.8 grade screw $(\mathrm{C}<=0.55 \%, \mathrm{~S}<=0.06 \%, \mathrm{P}<=0.05 \%)$.

Table.1 Chemical composition result of the fractured blot

\begin{tabular}{cccc}
\hline Chemical element & C & S & P \\
\hline Mass percentage(wt\%) & 0.36 & 0.016 & 0.022 \\
\hline
\end{tabular}

Hardness test on the fractured screw. The hardness was examined on transverse section of the screw arbor. Two positions were measured with results of 243.2HV10 and 243.9HV10 respectively, satisfying GB/T 3098.1-2000 standard for 6.8 grade screw(190-250HV).

SEM observation on the fractured screw. SEM observation was carried out on the screw fracture. It was found that the crack originated from the screw root on the waffle side, and the origination area had been squeezed to flat as shown in Fig.8. Fig.9 was the SEM morphology of propagation area of screw crack. It could be seen that there existed many cleavage planes with small tearing ridges, meaning that the propagating rate was high. Fig.10 illustrated a lot of dimples in the area of final crack stage.
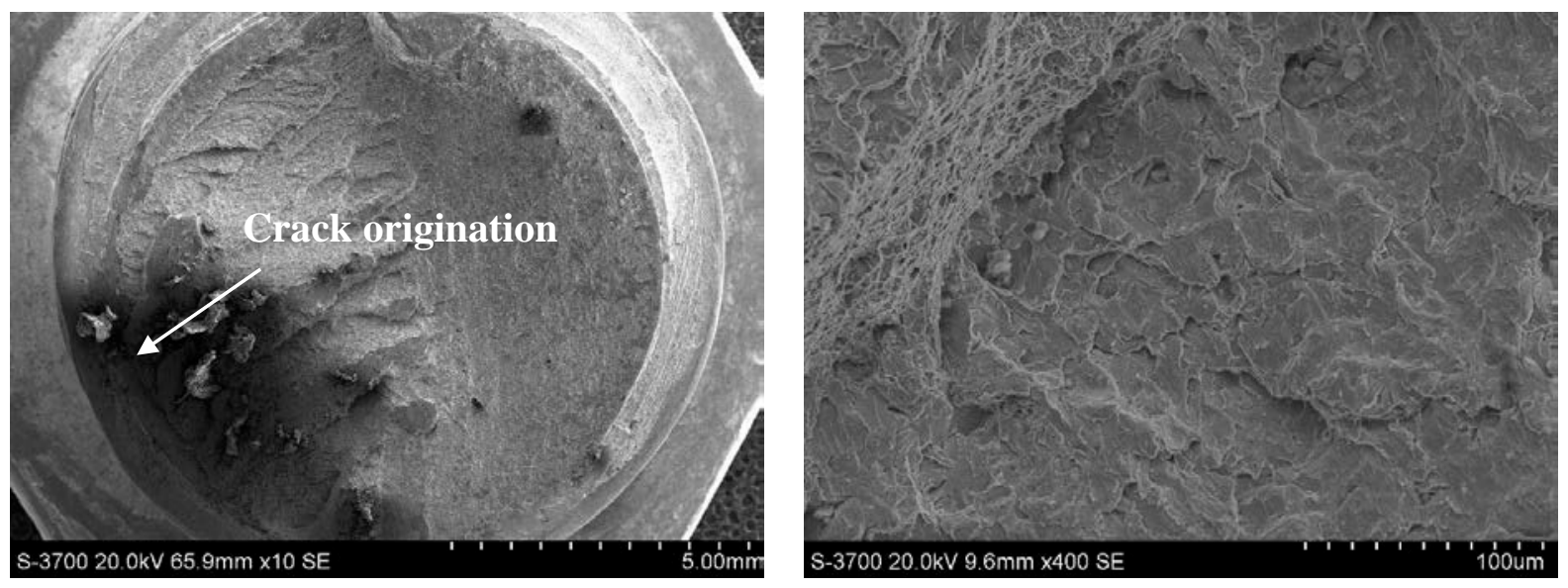

Fig.8 SEM morphology of the bolt fracture Fig.9 SEM morphology of crack propagation area

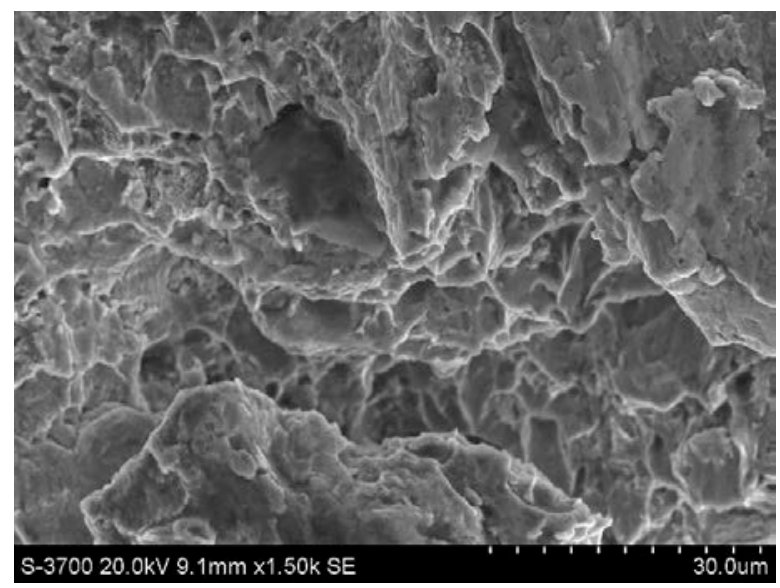

Fig.10 SEM morphology of the later stage of bolt cracking

\section{Discussions}

Macro observation showed that the screw endured violent lateral forward impacts leading to deformation and damage at the root. According to the estimation of connecting dimension, the crack position was on the verge of screw hole of the fixed frame, where not only bore maximum stress under impact but also was stress concentration position. When the screw was impacted heavily, flaw 
would appear and propagate quickly, that had been verified by SEM observation. When there was another impact stress, the screw would fracture due to inadequate strength and dropped finally.

\section{Conclusions and Suggestions}

The failure of the screw was because that the screw deformed and relaxed under large impact stress and finally fractured. Many elements such as improper choose of dimension, inadequate strength and relax may lead to screw fracture. It was suggested that larger screw be chosen and tightly rotated.

\section{References}

[1] Zhu aijun, Guo yaojie, Cheng chao, et al. Structural Analysis of the Bolting Truss-column of Substation, Journal of Chongqing Jianzhu University, 2008,30(1): 72-76.

[2] Lu binbin. Quick and Accurate Installation of Anchor Bolt in Substation Construction. Shanxi Architecture, 2005, 31(22):133-134.

[3] Ji ming. Tianjin electric power technology, 2006, (4):13-14.

[4] Xiaozun-Liang,Yinghai-Deng,Analysis and Resolution Scheme for the Cause of Breaking Bolts in $27.5 \mathrm{kV}$ Handcart Type Vacuum Circuit Breaker Made by ABB Company,Railway Standard Design,2005,(10):118-119

[5] Wang Xiaoqing,Xia Shuihua,Affecting factor and affecting mechanism for bolt fracture,Hoisting and Conveying Machinery,2010(11),45-49 